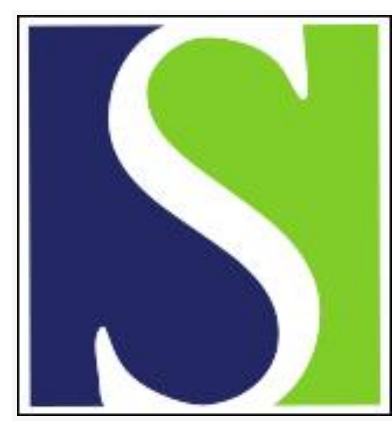

Scand J Work Environ Health 1981;7(1):64-67

https://doi.org/10.5271/sjweh.2564

Issue date: Mar 1981

A Swedish cancer-environment register available for research. by Wiklund K, Einhorn J, Wennström G, Rapaport E

Refers to the following text of the Journal: 1979;5(4):328-332

Key terms: cancer; cancer register; cancer-environment register; letter to the editor; Sweden

This article in PubMed: www.ncbi.nlm.nih.gov/pubmed/7313612

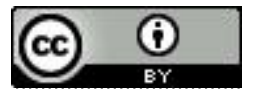


on the human and the animal organism. Gig sanit 6 (1976) 20-24.

2. Weiss MM, Petersen RC. Electromagnetic radiation emitted from video computer terminals. Am ind hyg assoc j 40 (1979) 300309.

Victor Lindén, MD, and Sturla

Rolfsen, BSc

National Labour Inspection

Local Office of Bergen

Møllendalsveien 6

N-5000 Bergen, Norway

\section{A Swedish cancer-environment register available for research}

\section{Motivation for the Cancer-Environment Register}

Certain conditions in Sweden and the other Scandinavtian countries furnish good opportunities for epidemiologic research on cancer. In the registration of cancer patients in the Swedish Cancer Register almost full coverage has been achieved $(3,4)$ and civil registration and other data sources enable a person to be traced.

The Cancer Register has, however, a number of shortcomings, the chief of them being the incompleteness of the information on occupation and place of domicile. The data relating to occupation are based on information that the patient furnishes on admission to the hospital, often at the reception desk. This is obviously not an occasion when either the patient or the hospital staff are likely to concern themselves with details of job and occupation. Reports to the Cancer Register are based on this information and are therefore often inconclusive on this point. In addition, until 1971 the place of domicile reported in the Cancer Register was not specific enough to be used in most epidemiologic studies.

It was decided to improve the information contained in the Cancer Register by merging it with a census. The 1960 census was selected for this purpose because it contains detailed information on occupation and place of domicile and includes other data which could be of interest in epidemiologic studies on the causes of cancer. The fact that the 1960 census was the first to be stored in an electronic retrieval system played an important role.
Reference was also made to the 1950 census, which has the advantage of offering a longer time lag between exposure and the actual manifestation of the disease.

\section{Legal obstacles}

Sweden has, as has many other countries, enacted strict and detailed legislation designed to protect the integrity and privacy of individuals registered in retrieval systems. Information in the Cancer Register of the National Board of Health and Welfare, in the 1960 census of the National Central Bureau of Statistics, and in the Total Population Register - essential factors in the establishment of the CancerEnvironment Register - is subject to this legislation, and approval of the Data Inspection Board was required to merge information from these registers. After a series of discussions the National Board of Health and Welfare and the National Central Bureau of Statistics drew up an agreement in November 1976 clarifying the forms which mutual cooperation would take, provided the Data Inspection Board authorized the establishment of the Cancer-Environment Register.

According to the terms of this agreement data from the Register can be released for scientific and research purposes, including epidemiologic studies. A special committee was formed within the National Board of Health and Welfare to include members of both agencies. This committee must be responsible for dealing with the disclosure of information and is required to ensure that adequate precautions are taken to maintain secrecy and to prevent the unauthorized disclosure of information.

Before the merging operation and the release of information from the Register for research work, a detailed check was made of the identity of persons in the Cancer Register.

Correction of personal identities in the Cancer Register before the merging operation

The Cancer Register for the period 19611973 contains about 385,000 persons, and the 1960 census about 7,500,000. Every person living in Sweden has an individual per- 
sonal identification number. During the merging operation individuals in both registers were identified by this nine-digit number. In a preliminary merging operation, $7 \%$ of the persons in the Cancer Register could not be identified in the 1960 census. This could, for the most part, be due to incomplete, or complete but inaccurate, numbers in the Register, changes in identification numbers after the 1960 census, and immigration to Sweden since 1960. From parish records, the National Tax Boards Immigrant Register, the Total Population Register and other sources, correct and complete identification numbers were supplemented for persons not identified in the preliminary merging operation. On completion of this work about $99 \%$ of the persons in the Cancer Register had been identified in the 1960 census. Despite these efforts, when the two registers were merged in the autumn of 1978, 4,700 persons in the Cancer Register could not be identified in the 1960 census. This figure represents only about $1 \%$ of the total.

\section{Contents of the Cancer-Environment Register}

The Cancer-Environment Register (CER) contains all the entries in the Cancer Register made between 1961 and 1973. It also contains the following information from the 1960 Census:

\section{Occupation}

Main occupation during the year

Economic activity

Type of activity

Occupational status

Gainful employment

Domicile (county, municipality, parish)

Place of work (county, municipality, parish) Country of birth

Higher education

Gainful employment is listed as the binary variable Gainfully Employed and Not Gainfully Employed. A person is classed as gainfully employed if he or she worked at least half the normal hours of work during the census week in October 1960.

The classification of occupation closely follows the International Standard Classification of Occupations (ISCO). A threelevel classification is applied, designated by a three-digit code. The classification criteria are based on the Nordic Classification of Occupations.
The main occupation during the year is coded in the same manner as occupation. Whereas the entries for occupation relate only to the census week, those for main occupation cover the whole year and provide additional information on those persons not gainfully employed during the census week but working for part of the year.

Economic activity is a classification which follows Indexes to the International Standard Classification of All Economic Activities (ISIC). A three-level classification with a three-digit code is applied.

Occupational status offers a more detailed breakdown of the gainfully employed, including employers and employees. Employees are classified as supervisors and other salary and wage earners. Employers are divided into those with or without employees.

Type of activity indicates the activities of those not gainfully employed, for example, housework, military service, and continuing education.

Education is a binary variable indicating tertiary education or not. The Register does not indicate the type of education received.

Domicile is reported with a six-digit code indicating county, municipality, and parish.

Place of work is coded in the same way as domicile.

Some scientists who will use the Register might wish to exclude persons not born in Sweden from certain studies. A binary code would be sufficient for such selection. Reasons for specifying the country of birth were, however, considered to be valid. Some countries have a higher cancer incidence than others, and it has been shown that, for certain types of cancer, immigrants tend to retain the incidence rate for their country of origin, whereas for other types the rate adjusts to that of their new country of domicile. Although the number of persons immigrating to Sweden is not large, interest in information on their country of origin was considered great enough to justify its inclusion in the Register.

The inclusion of higher education was motivated by recent observations that the incidence of certain types of tumors, as malignant lymphogranulomatosis, might 
be higher among persons with a university education, as also is the incidence of some virus diseases, such as infectious mononucleosis.

\section{Quality control of personal identity}

A match between a person in the Cancer Register and one in the 1960 census is no guarantee of accuracy. An inaccurate match may be due to an incorrect personal identification number in either or both of the Registers. Before the CER could be used, its quality in this respect had to be checked and the proportion of incorrect matches estimated. Because of the large size of the Register, sampling was the only practicable method of achieving suoh an estimation. The identity of the individuals was checked against the original 1960 census forms, cancer reports, and local parish records. A random-sample test disclosed that $0.45 \%$ of the matches were inaccurate. It is safe to conclude that this low percentage of inaccurate matches would have no appreciable effect in the majority of studies based on the Register. Moreover, these inaccurate matches are randomily distributed between the different diagnosis, sex and age groups.

\section{Release of information}

The purpose of the CER is to provide a source of information for scientists investigating the relationship between cancer and the environment, and in particular the place of work and domicile. Information in the Register is therefore available to all those engaged in this type of research. Requests for access to information are submitted to Kerstin Wiklund, National Board of Health and Welfare Planning Division 3, Cancer-miljöregistret, S-106 30 Stockholm, Sweden. All requests are considered by the CER Committee.

Information can be released in the form of print-out, microfiche copies, tape, or statistical tables. Before information stored on tape can be released, the permission of the Swedish Data Inspection Board is however required. The Committee is obligated to issue directives on the storage of data. If the user intends con- tacting persons listed in the Register, he must seek the permission of the Committee, which stipulates the conditions under which such contact may be made. The Committee is also obligated to review certain types of material prior to general publication. The reviewing powers of the Committee are, however, restricted to matters of disclosure and the infringement of privacy.

\section{Limitations and defects}

The CER contains information derived from cancer reports forwarded to the National Board of Health and Welfare by physicians, and the information on, for example, occupation, type of activity, and place of work supplied by respondents on the census form. The Register suffers from the defects inherent in this type of information. However, a quality evaluation of the two registers has revealed a high level of accuracy $(1,3,4)$.

A study of the information in the CER is hardly likely to lead to any definitive conclusions. At best it could contribute to the establishment of hypotheses and furnish a basis for studies drawing on other sources of information. On the other hand, a combination of variables such as, for instance, occupation, economic activity and place of work can facilitate the identification of high-risk groups. The information in the 1960 census applies to a particular week in October 1960 during which the count was made. As regards, for example, the mean period of employment, the flow of labor between various occupational and economic activity groups before and after this census week resulted in mixing and dilution effects. There are, in this respect, differences between occupational and economic activity groups and probably also between geographic areas. There are also considerable differences between individuals with the same occupational career as to exposure to a certain agent. It is also important to be aware of the crudeness of using occupational titles in etiologic research (2). Observations based on studies of the CER will however usually need to be supplemented by field studies, analysis of a random verification of selected information, cohort studies, poll surveys, and the like. 


\section{Further development}

A background register was devised to improve the usefulness of the CER. This register lists the total number of individuals in the 1960 census with the combination of variables taken from the CER. The question of further up-dating of the CER with information from other national census records has not yet been raised for discussion.

It is our hope that the Swedish CER will increase the potential for epidemiologic studies on cancer.

\section{Summary}

The National Board of Health and Welfare and the National Central Bureau of Statistics in Sweden have jointly established a register containing, in addition to the data of the Swedish Cancer Register, information on occupation, economic activity, place of domicile, etc, from the 1960 population census. In the autumn of 1978 this Register was made available for interested scientists in all countries. It can be used for epidemiologic studies on the relationship that occupation, place of domicile, and similar factors may bear to the incidence of different types of cancer. The project was designated the Cancer-
Environment Register. The present paper contains a synopsis of this register.

\section{References}

1. Brivkalne M. The control study made in connection with the 1960 census of population. National Central Bureau of Statistics, Stockholm 1964. (Statistical report B 1964: 16).

2. Holmberg PC, Hernberg S. Congenital defects and occupational factors. Scand $j$ work environ health 5 (1979) 328-332.

3. Mattsson, B. Completeness of registration in the Swedish Cancer Registry. National Central Bureau of Statistics, Stockholm 1977 (Statical report HS 1977: 15).

4. Mattsson, B. Reliability of identity number registration in the Swedish Cancer Registry. National Central Bureau of Statistics, Stockholm 1977. (Statistical report HS 1977: 1).

Kerstin Wiklund, BA, Jerzy Einhorn, MD.

Gunnar Wennström, MD

National Board of Health and Welfare

Cancer-Environment Registry

S-106 30 Stockholm, Sweden

and

Edmund Rapaport, LLB, MPolSc

National Central Bureau of Statistics

Stockholm, Sweden 